\title{
Effects of 6 months of abatacept treatment on aortic stiffness in patients with rheumatoid arthritis
}

This article was published in the following Dove Press journal:

Biologics:Targets and Therapy

29 November 2013

Number of times this article has been viewed

\author{
Sylvain Mathieu ${ }^{1,2}$ \\ Marion Couderc ${ }^{1,2}$ \\ Baptiste Glace ${ }^{1,2}$ \\ Bruno Pereira ${ }^{2,3}$ \\ Anne Tournadre ${ }^{1,2}$ \\ Jean-Jacques Dubost ${ }^{1,2}$ \\ Martin Soubrier ${ }^{1,2}$ \\ 'Department of Rheumatology, \\ Gabriel-Montpied Hospital, ${ }^{2}$ Faculty \\ of Medicine, University Clermont I, \\ ${ }^{3}$ Délégation de la Recherche Clinique, \\ Gabriel-Montpied Hospital, \\ Clermont-Ferrand, France
}

Background: Systemic inflammation plays an important role in the increased cardiac risk observed in rheumatoid arthritis (RA). Effective control of inflammation and disease activity may be of benefit in reducing cardiovascular risk in RA patients.

Objective: Our study was conducted in patients with active RA to investigate the effects of 24-week abatacept treatment on aortic stiffness measured by pulse wave velocity (PWV).

Results: The study included 21 patients, of whom 17 were females, with a mean age of 65.2 \pm 13.7 years. Ten patients had positive rheumatoid factors, 16 positive anti-citrullinated protein antibodies, and 19 presented an erosive form of RA. Sixteen patients were nonresponders to anti-tumor necrosis factor-alpha treatments. After 6 months of abatacept treatment, there was a significant increase in PWV levels $(9.8 \pm 2.9$ versus $8.5 \pm 3.9 \mathrm{~m} / \mathrm{second} ; P=0.02)$. A nonsignificant increase in total cholesterol and low-density lipoprotein cholesterol was observed. There was also a significant increase in high-density lipoprotein cholesterol levels, which led to a nonsignificant decrease in atherogenic index. The improvement in disease activity was significant, and there was a decrease of systemic inflammatory parameters, but without reaching statistical significancy. Changes in PWV were significantly correlated with changes in Disease Activity Score on 28 joints based on erythrocyte sedimentation rate $(r=0.46 ; P=0.035)$ and in high-density lipoprotein cholesterol ( $r=-0.38 ; P=0.046$ ). No correlation was observed with changes in C-reactive protein and in other parameters of lipid profile or in steroid dose.

Conclusion: The worsening of aortic stiffness found after 6 months of abatacept therapy might be due to an insufficient decrease in systemic inflammation.

Keywords: arterial stiffness, cardiovascular risk markers, systemic inflammation, atherogenic index

\section{Introduction}

Rheumatoid arthritis (RA) is characterized by an increased cardiovascular risk and impaired vascular function. ${ }^{1-3}$ The reasons for this endothelial dysfunction in RA are multifactorial and not fully understood. Currently, it is not certain whether systemic inflammation, which was previously thought to play a role, ${ }^{4,5}$ is involved, and a recent review concluded that the link between systemic inflammation and vascular function was not fully supported by the literature. ${ }^{6}$ Likewise, we recently reported that, despite significant improvements in systemic inflammation and disease activity, there was no change in aortic stiffness after 6 and 12 months of rituximab therapy in 33 RA patients. ${ }^{7}$ Persisting aortic stiffness might have been due to a pro-atherogenic lipid profile caused by rituximab treatment. ${ }^{7}$
Correspondence: Sylvain Mathieu Hôpital Gabriel-Montpied, Service de Rhumatologie, Place H Dunant, 63000 Clermont-Ferrand, France Tel +3347375 I4 88 Fax +3347375 I489

Email smathieu@chu-clermontferrand.fr 
Abatacept is another biotherapy that is known to be effective on systemic inflammation and disease activity in RA.

This study was aimed at assessing the effects of 24 weeks of abatacept therapy on pulse wave velocity (PWV), a measure of aortic stiffness and lipid profile, in RA patients.

\section{Patients and methods}

RA patients who fulfilled the American College of Rheumatology 1987 revised criteria were eligible for enrollment. ${ }^{8}$ Moreover, to be included in the study, patients had to have received more than two unsuccessful anti-tumor necrosis factor (TNF)-alpha treatments or have contraindications to those treatments and persistent active RA (a Disease Activity Score on 28 joints based on erythrocyte sedimentation rate $\left[\mathrm{DAS} 28_{\mathrm{ESR}}\right]$ or Disease Activity Score on 28 joints based on C-reactive protein [DAS28 ${ }_{\mathrm{CRP}}$ ] >3.2). Patients were treated with abatacept, receiving monthly intravenous infusions according to medical practitioners' opinions for 6 months. Clinical assessment, laboratory examinations, and aortic stiffness were recorded at baseline and after 24 weeks of treatment. The study was approved by the local Research Ethics Committee of the Gabriel-Montpied Hospital (Clermont-Ferrand, France), and all subjects provided written informed consent.

\section{Clinical assessment}

Disease duration and medications were recorded. DAS28 $8_{\mathrm{ESR}}$ and DAS2 $8_{\mathrm{CRP}}$ were determined at baseline, and at 6 months post-treatment. The number of tender joints and swollen joints was also recorded for each patient. The global level of disease activity and the level of pain were self-assessed by the patients using a $100 \mathrm{~mm}$ horizontal visual analog scale. Patients were considered in remission if their DAS28 $8_{\mathrm{ESR}}$ or DAS2 $8_{\text {CRP }}<2$.6. They were considered to have systemic inflammation if their C-reactive protein (CRP) level was higher than $10 \mathrm{mg} / \mathrm{L}$ and/or their erythrocyte sedimentation rate (ESR) level was higher than $30 \mathrm{~mm} / \mathrm{h}$.

\section{Noninvasive vascular assessment PWV}

To avoid interobserver variability, all measurements were performed by the same examiner, Emilie Rabois, clinical research assistant, who was informed by an experienced cardiologist and blinded to the clinical characteristics of the subjects. The SphygmoCor Arterial Waveform Analysis System (AtCor Medical, Sydney, Australia) was used to perform pulse wave analysis, and blood pressure was measured in the supine position at the brachial artery using a sphygmomanometer.
PWV was measured using the carotid-to-femoral velocity method, as reported by Wilkinson et al. ${ }^{9}$ The distance (D) covered by the waves was assimilated to the distance measured between the common carotid artery and the right femoral artery. The time delay ( $\mathrm{t}$ ) was measured between the feet of the two waveforms. Thus, PWV was calculated as $\mathrm{PWV}=\mathrm{D}$ (meters $) / \mathrm{t}($ seconds $)$.

\section{Laboratory examinations}

Venous blood was sampled for determining the CRP serum concentrations, ESR, and lipid profile (total cholesterol, low-density lipoprotein [LDL] cholesterol, high-density lipoprotein [HDL] cholesterol, and triglycerides) in the morning, after an overnight fasting. The atherogenic index (total cholesterol/HDL cholesterol) was then calculated.

\section{Statistical analysis}

Quantitative variables were expressed as mean \pm standard deviation (SD) or median and interquartile range and categorical variables as number of patients (\%). To compare the time course evolution (baseline, 6 months) of different parameters, a repeated-measure analysis of variance was used for between-group differences (including the effects of time, group [remission or inflammation], interaction [group $\times$ time], and subject) followed by paired $t$-test or Wilcoxon test for within-group differences. When the normality of a parameter was not achieved using the Shapiro-Wilk test (eg, ESR and CRP), two options were considered; either 1) $\log$ transformation was performed and previous models were used or 2) generalized linear mixed models were implemented for parameters without a Gaussian or log-transformed normal distribution. Residual normality was checked for all models presented in this article. Spearman's correlation test was used to determine the association between changes in PWV after 6 months of treatment and changes in other parameters. Power analyses were conducted to determine whether the sample size was sufficient to detect changes over time. A $P$-value of $<0.05$ (two-tailed) was considered statistically significant. Statistical analysis was performed using Stata software (version 10; StataCorp LP, College Station, TX, USA).

\section{Results}

The study included 21 RA patients, of whom 17 (81\%) were female, with a mean age of $65.6 \pm 13.6$ years and disease duration of $21.5 \pm 10.0$ years. Among these patients, ten (47.6\%) had positive rheumatoid factors, $16(76.2 \%)$ had 
positive anti-cyclic citrullinated protein (CCP) antibodies, and 19 presented with an erosive form of RA. Sixteen patients (76.2\%) were nonresponders to anti-TNF-alpha treatments, and five had contraindications to these treatments. At baseline, methotrexate was used in 12 patients (57.1\%) at a median dose of $10 \mathrm{mg} /$ week, and $86 \%$ of patients were treated with steroids at a mean dose of $9.7 \pm 9.2 \mathrm{mg} /$ day. Baseline characteristics of the 21 included RA patients are summarized in Table 1.

After 6 months of abatacept treatment, there was a significant increase in PWV levels in the 21 RA patients $(9.8 \pm 2.9$ at 6 months versus [vs] $8.5 \pm 3.9 \mathrm{~m} / \mathrm{second}$ at baseline; $P=0.02$; Table 2). There was an increase in all parameters of lipid profile, but this increase was only significant for HDL cholesterol level $(1.86 \pm 0.55$ at 6 months vs $1.61 \pm 0.46 \mathrm{mmol} / \mathrm{L}$ at baseline; $P=0.03$ ), which led to a nonsignificant decrease

Table I Baseline characteristics of rheumatoid arthritis patients treated with abatacept

\begin{tabular}{|c|c|}
\hline Characteristic & $\begin{array}{l}\text { Abatacept } \\
\text { group }(n=2 I) *\end{array}$ \\
\hline Age, years & $65.2 \pm 13.7$ \\
\hline Male/female & $4 / 17$ \\
\hline Smoking status, $\mathrm{n}(\%)$ & I (4.8\%) \\
\hline $\mathrm{BMI}, \mathrm{kg} / \mathrm{m}^{2}$ & $23.8 \pm 4.7$ \\
\hline Systolic blood pressure, $\mathrm{mmHg}$ & $140.9 \pm 21.6$ \\
\hline Diastolic blood pressure, $\mathrm{mmHg}$ & $80.7 \pm 10.5$ \\
\hline History of cardiovascular disease, $n(\%)$ & $3(14.3 \%)$ \\
\hline Disease duration, years & $21.5 \pm 10.0$ \\
\hline Systolic BP, mmHg & $140.0 \pm 21.6$ \\
\hline Diastolic BP, mmHg & $80.7 \pm 10.5$ \\
\hline Positive RF, n (\%) & $10(47.6)$ \\
\hline Positive anti-CCP, n (\%) & $16(76.2)$ \\
\hline Erosive RA, n (\%) & $19(90.5)$ \\
\hline Swollen joint count & $6.4 \pm 3.6$ \\
\hline $\mathrm{ESR}, \mathrm{mm} / \mathrm{h}$ & $34.2 \pm 39.5$ \\
\hline CRP, mg/L & $21.4 \pm 39.4$ \\
\hline DAS28 $8_{\text {ESR }}$ & $5.07 \pm 1.10$ \\
\hline DAS28 ${ }_{\text {CRP }}$ & $4.68 \pm 0.87$ \\
\hline Statins or lipid-lowering treatments, $\mathrm{n}(\%)$ & $4(19.0)$ \\
\hline \multicolumn{2}{|l|}{ DMARDS, n (\%) } \\
\hline Methotrexate & $12(57.1)$ \\
\hline Leflunomide & $2(9.5)$ \\
\hline Hydroxychloroquine & $4(20.0)$ \\
\hline Sulfasalazine & $2(9.5)$ \\
\hline Combination & $3(14.3)$ \\
\hline None & $5(23.8)$ \\
\hline Corticosteroids, n (\%) & $18(85.7)$ \\
\hline $\mathrm{mg} /$ day & $9.7 \pm 9.2$ \\
\hline NSAIDs, n (\%) & $2(9.5)$ \\
\hline
\end{tabular}

Note: *Values are expressed as mean \pm standard deviation $(\mathrm{SD})$ unless otherwise specified.

Abbreviations: anti-CCP, anti-cyclic citrullinated protein; BMI, body mass index; BP, blood pressure; CRP, C-reactive protein; DAS28 ${ }_{\text {CRP }}$, Disease Activity Score on 28 joints based on C-reactive protein; DAS28 ${ }_{\text {ESR }}$, Disease Activity Score on 28 joints based on erythrocyte sedimentation rate; DMARDs, disease-modifying antirheumatic drugs; ESR, erythrocyte sedimentation rate; NSAIDs, non-steroidal anti-inflammatory drugs; RF, rheumatoid factor; RA, rheumatoid arthritis; SD, standard deviation; n, number.
Table 2 Differences in parameters after 6 months of abatacept treatment

\begin{tabular}{|c|c|c|c|}
\hline \multirow[t]{2}{*}{ Parameter } & \multicolumn{2}{|c|}{$\begin{array}{l}\text { Abatacept therapy } \\
(n=2 I)\end{array}$} & \multirow{2}{*}{$\begin{array}{l}\text { Paired } t \text {-test or } \\
\text { Wilcoxon test } \\
P \text {-value }\end{array}$} \\
\hline & Baseline & 6 months & \\
\hline $\mathrm{PWV}, \mathrm{m} / \mathrm{s}$ & $8.5 \pm 3.9$ & $9.8 \pm 2.9$ & 0.02 \\
\hline Total cholesterol, $\mathrm{mmol} / \mathrm{L}$ & $4.95 \pm 0.99$ & $5.36 \pm 0.84$ & 0.08 \\
\hline HDL cholesterol, mmol/L & $1.61 \pm 0.46$ & $1.86 \pm 0.55$ & 0.03 \\
\hline LDL cholesterol, mmol/L & $2.69 \pm 0.64$ & $2.79 \pm 0.65$ & 0.68 \\
\hline Triglycerides, mmol/L & $1.33 \pm 0.87$ & $1.47 \pm 1.02$ & 0.99 \\
\hline Atherogenic index & $3.26 \pm 0.91$ & $3.11 \pm 1.10$ & 0.31 \\
\hline $\mathrm{TJC}$ & $7.1 \pm 5.2$ & $2.8 \pm 3.3$ & $<0.00$ I \\
\hline SJC & $6.4 \pm 3.6$ & $3.5 \pm 3.8$ & $<0.00 \mathrm{I}$ \\
\hline Patient pain VAS & $66.4 \pm 16.1$ & $40.9 \pm 22.8$ & $<0.001$ \\
\hline Patient activity VAS & $65.3 \pm 17.3$ & $40.1 \pm 22.2$ & $<0.00$ I \\
\hline $\mathrm{ESR}, \mathrm{mm} / \mathrm{h}$ & $34.2 \pm 39.5$ & $26.5 \pm 28.1$ & 0.12 \\
\hline CRP, mg/L & $21.4 \pm 39.4$ & $11.7 \pm 15.0$ & 0.72 \\
\hline DAS28 ${ }_{\mathrm{ESR}}$ & $5.1 \pm 1.1$ & $3.7 \pm 1.2$ & $<0.00$ I \\
\hline DAS28 ${ }_{\text {CRP }}$ & $4.7 \pm 0.9$ & $3.4 \pm 1.1$ & $<0.00 \mathrm{I}$ \\
\hline Steroids dose, mg/day & $9.7 \pm 9.2$ & $6.9 \pm 6.3$ & 0.01 \\
\hline
\end{tabular}

Notes: Values are expressed as mean \pm standard deviation. Values in bold are significant.

Abbreviations: CRP, C-reactive protein; DAS28 $28_{\text {CRP, }}$ Disease Activity Score on 28 joints based on C-reactive protein; DAS2 $8_{\mathrm{ESR}}$, Disease Activity Score on 28 joints based on erythrocyte sedimentation rate; ESR, erythrocyte sedimentation rate; HDL, high-density lipoprotein; LDL, low-density lipoprotein; PWV, pulse wave velocity; SJC, swollen joint count; TJC, tender joint count; VAS, visual analog scale.

in atherogenic index. No change was found in blood pressure or body mass index. Disease activity improved, as shown by a significant decrease in DAS28 $8_{\mathrm{ESR}}$ and DAS28 $8_{\mathrm{CRP}}$ and also in steroid dose ( $6.9 \pm 6.3$ at 6 months vs $9.7 \pm 9.2 \mathrm{mg} / \mathrm{L}$ at baseline; $P=0.01)$. There was a decrease in systemic inflammation parameters, but not to a level of significance (CRP: $11.7 \pm 15.0$ at 6 months vs $21.4 \pm 39.4 \mathrm{mg} / \mathrm{L} ; P=0.72$ and $\mathrm{ESR}: 26.5 \pm 28.1$ at 6 months vs $34.2 \pm 39.5 \mathrm{~mm} / \mathrm{h}$ at baseline; $P=0.12$ ).

Changes in PWV were positively correlated to changes in DAS2 $8_{\mathrm{ESR}}(P=0.035)$ and negatively correlated with changes in HDL cholesterol $(P=0.046)$. No correlation was observed with changes in CRP and in other parameters of lipid profile or in steroid dose (Table 3). For the six patients who achieved disease remission after 6 months of treatment, PWV remained unchanged $(9.3 \pm 3.4 \mathrm{~m} / \mathrm{second}$ at baseline, $10.0 \pm 4.4$ at 6 months; $P=0.25$; Table 3 ). Conversely, in the 15 patients who did not achieve disease remission at 6 months, PWV increased significantly $(8.19 \pm 4.14 \mathrm{~m} / \mathrm{second}$ vs $9.66 \pm 2.4$ at baseline, and 6 months, respectively; $P=0.04$ ). Regardless of whether patients still had systemic inflammation after 6 months of abatacept treatment, there was no change in PWV (Table 4).

\section{Discussion}

Despite improvements in systemic inflammation, PWV - "the most accurate non-invasive marker of aortic 
Table 3 Correlation between changes in pulse wave velocity (PWV) after 6 months of abatacept treatment and changes in other parameters

\begin{tabular}{lll}
\hline Changes in parameters & \multicolumn{2}{l}{ Changes in PWV } \\
\cline { 2 - 3 } & $\boldsymbol{r}$ & $\mathbf{P}$-value \\
\hline DAS28 $_{\text {ESR }}$ & 0.46 & $\mathbf{0 . 0 3 5}$ \\
DAS28 $_{\text {CRP }}$ & 0.43 & 0.058 \\
CRP & 0.02 & 0.93 \\
Total cholesterol & -0.06 & 0.83 \\
LDL cholesterol & 0.02 & 0.94 \\
HDL cholesterol & -0.39 & $\mathbf{0 . 0 4 6}$ \\
Triglycerides & -0.33 & 0.20 \\
Atherogenic index & 0.11 & 0.67 \\
Steroids dose & 0.04 & 0.87 \\
\hline
\end{tabular}

Note: Spearman's test; values in bold are significant.

Abbreviations: CRP, C-reactive protein; DAS28 ${ }_{\text {CRP }}$, Disease Activity Score on 28 joints based on C-reactive protein; DAS28 $8_{\mathrm{ESR}}$, Disease Activity Score on 28 joints based on erythrocyte sedimentation rate; HDL, high-density lipoprotein; LDL, lowdensity lipoprotein.

stiffness" ${ }^{\prime 10,11}$ - increased in this study after 6 months of abatacept treatment, which was probably due to the insufficient decrease in systemic inflammation. However, we could not exclude the worsening effect of the lipid profile, with an increase in total and LDL cholesterol. A positive effect was found on HDL cholesterol level after 6 months of treatment, but this was insufficient to significantly improve the atherogenic index.

As expected, abatacept significantly improved disease activity parameters such as swollen joints and DAS28, and also decreased systemic inflammation parameters (ESR

Table 4 Changes of pulse wave velocity (PWV) in rheumatoid arthritis patients according to disease activity and systemic inflammation

\begin{tabular}{|c|c|c|c|}
\hline Time & $\mathbf{n}$ & Mean \pm SD & $P$-value* \\
\hline \multicolumn{4}{|c|}{ Patients in disease remission (DAS28 $<2.6$ ) at 6 months } \\
\hline \multicolumn{4}{|c|}{$\mathrm{PWV}, \mathrm{m} / \mathrm{s}$} \\
\hline Baseline & 6 & $9.3 \pm 3.4$ & \\
\hline 6 months & 6 & $10.0 \pm 4.4$ & 0.25 \\
\hline \multicolumn{4}{|c|}{ Patients not in disease remission (DAS28 $>2.6$ ) at 6 months } \\
\hline \multicolumn{4}{|c|}{$\mathrm{PWV}, \mathrm{m} / \mathrm{s}$} \\
\hline Baseline & 15 & $8.19 \pm 4.14$ & \\
\hline 6 months & 15 & $9.66 \pm 2.40$ & 0.04 \\
\hline \multicolumn{4}{|c|}{ Patients with no systemic inflammation at 6 months } \\
\hline \multicolumn{4}{|c|}{$\mathrm{PWV}, \mathrm{m} / \mathrm{s}$} \\
\hline Baseline & 12 & $8.37 \pm 2.93$ & \\
\hline 6 months & 12 & $9.42 \pm 3.47$ & 0.10 \\
\hline \multicolumn{4}{|c|}{ Patients with systemic inflammation at 6 months } \\
\hline \multicolumn{4}{|c|}{$\mathrm{PWV}, \mathrm{m} / \mathrm{s}$} \\
\hline Baseline & 9 & $8.7 \pm 5.1$ & \\
\hline 6 months & 9 & $10.2 \pm 2.3$ & 0.10 \\
\hline
\end{tabular}

Note: *Paired $t$-test or Wilcoxon test after repeated-measure analysis of variance. Abbreviations: DAS28, Disease Activity Score on 28 joints; SD, standard deviation; $\mathrm{ms}, \mathrm{m} / \mathrm{second}$; number. and CRP), although not to a significant degree. This lack of statistical significance could explain the lack of improvement in parameters of subclinical atherosclerosis. Atheroma is recognized to be an inflammatory process and CRP a good predictor of cardiovascular event occurrence. Studies that assessed the effects of biotherapies (ie, rituximab, tocilizumab, or TNF-alpha inhibitors) on aortic stiffness in RA revealed variable changes in PWV or augmentation index, but most of the time found an improvement in aortic stiffness, with a significant decrease in systemic inflammation. ${ }^{12-14}$

These results tend to indicate the importance of decreasing systemic inflammation and disease activity in RA patients and the role of this in atherosclerosis. Recently, a study confirmed that a high circulating concentration of interleukin 6 was associated with an increased risk of coronary heart disease. ${ }^{15}$ The second important reason to intensify the treatment of RA, and especially using biologic therapies, is to obtain a tapering of steroids. In this study, abatacept treatment permitted a significant decrease in steroid dose. However, this beneficial effect produced no improvement in PWV, as shown by a nonsignificant correlation.

The deleterious effect of dyslipidemia that this study found after abatacept treatment may be the reason for the lack of aortic stiffness change. Several studies have reported a post-biotherapy atherogenic lipid profile that could counterbalance the benefit of decreasing systemic inflammation for aortic stiffness. To the best of our knowledge, no other study has assessed the effects of abatacept on lipid profile.

Conversely, the deleterious effects of tocilizumab, another RA biotherapy that is known to frequently increase total and LDL cholesterol levels, has inspired recommendations for controlling lipid profile after 3 months of tocilizumab treatment in RA patients. ${ }^{13,16-18}$ However, despite this induced atherogenic lipid profile after tocilizumab treatment, aortic stiffness has been reported to have improved in two recent studies. ${ }^{13-14}$

Regarding anti-TNF-alpha treatment, the effects of this on aortic stiffness remain controversial, but a recent literature review suggests there may be a beneficial effect. ${ }^{12}$ Changes in the lipid profile after TNF-alpha inhibitors have also been shown to be variable. One study has revealed an improvement in the lipid pattern, ${ }^{19}$ and another a progression toward an atherogenic profile; ${ }^{20}$ in still others, no significant effect on the atherogenic index was reported. ${ }^{21-25}$ In a recent meta-analysis, significant change after TNF-alpha blockade was found. ${ }^{26}$ In another meta-analysis, Daïen et al noted increased HDL and total cholesterol levels after long-term TNF-alpha blockade treatment, but no change in LDL levels 
or atherogenic index. ${ }^{27}$ Similarly, a significant change in total cholesterol and HDL cholesterol levels has also been shown in a meta-analysis by van Sijl et al. ${ }^{28}$

For rituximab, results are less numerous, but remain contradictory. Kerekes et al found decreased total cholesterol and increased HDL cholesterol levels, ${ }^{29}$ although a proatherogenic lipid profile was noted in another study of $33 \mathrm{RA}$ patients after 6 and 12 months of treatment. ${ }^{7}$ Schimmel and Yazici reviewed the published data on lipid profile changes in RA patients treated with biological disease-modifying antirheumatic drugs and observed an increase in lipid levels between baseline and study end in these patients. ${ }^{30}$ However, in most of these studies, no significant change in atherogenic index from baseline to end of study was found.

The clinical implications of this finding with regard to cardiovascular outcomes are not clear. Anti-TNF-alpha blockade treatments have been reported to have a beneficial effect on cardiovascular mortality and morbidity in RA patients. ${ }^{31}$ The reason for this improvement in the cardiovascular risk profile remains uncertain, but is probably due to decreased systemic inflammation. ${ }^{31}$

The study reported here found that PWV worsened in patients who did not achieve remission, but not in patients with disease remission. Effective control of inflammation could certainly be of benefit in reducing cardiovascular risk in RA patients. However, the deleterious effects of biotherapies on lipid profile in RA patients need to be clarified, especially for TNF-alpha inhibitors and rituximab. It appears necessary to monitor the lipid profile in RA patients regularly in order to initiate an appropriate treatment in case of dyslipidemia.

\section{Limitations}

The small size of the sample (21 patients) may have limited statistical power. However, the number of patients we included is far from unreasonable compared with some earlier studies on the effects of other biological therapies (Kerekes $^{7} \mathrm{n}=5$, Kawashiri ${ }^{16} \mathrm{n}=9$, or Soubrier ${ }^{23} \mathrm{n}=29$ ). Moreover, as far as we are aware, this is the first study to have assessed the effects of abatacept on lipid profile in RA patients. While the assessment of 21 RA patients after 6 months of treatment was indeed insufficient to draw strong conclusions from, it still gives some relevant indication of the effects of abatacept.

Another limitation of our study was the lack of a control group, thereby rendering the determination of the time needed to assess changes in stiffness more difficult. We have recently reported the effects of rituximab treatment on PWV in RA patients. ${ }^{7}$ An indirect comparison to this previous study using the rituximab group as a diseased control group might be interesting. After rituximab treatment, no change was observed in PWV after either 6 or 12 months, even when RA patients achieved disease remission at 6 or 12 months.

\section{Conclusion}

In this study - to our knowledge, the first to assess the effects of abatacept treatment on aortic stiffness in RA patients - the treatment did not limit or decrease aortic stiffness, a marker of cardiovascular risk. The reason for these findings could be the insufficient decrease in systemic inflammation. However, the increase in PWV warrants review and close monitoring of the modifiable cardiovascular risk factors, especially the lipid profile, in RA patients treated with abatacept.

\section{Acknowledgment}

We would like to acknowledge Emilie Rabois, clinical research assistant, for her support in the aortic stiffness assessment.

\section{Disclosure}

The authors declare no conflicts of interest in this work.

\section{References}

1. Meune C, Touzé E, Trinquart L, Allanore Y. Trends in cardiovascular mortality in patients with rheumatoid arthritis over 50 years: a systematic review and meta-analysis of cohort studies. Rheumatology. 2009;48(10):1309-1313.

2. Kitas GD, Gabriel SE. Cardiovascular disease in rheumatoid arthritis: state of the art and future perspectives. Ann Rheum Dis. 2011;70(1): $8-14$.

3. Van Doornum S, McColl G, Jenkins A, Green DJ, Wicks IP. Screening for atherosclerosis in patients with rheumatoid arthritis: comparison of two in vivo tests of vascular function. Arthritis Rheum. 2003;48(1): $72-80$.

4. Forte L, Cimmino G, Loffredo F, et al. C-reactive protein is released in the coronary circulation and causes endothelial dysfunction in patients with acute coronary syndromes. Int J Cardiol. 2011;125(1):7-12.

5. Solomon DH, Kremer J, Curtis JR, et al. Explaining the cardiovascular risk associated with rheumatoid arthritis: traditional risk factors versus markers of rheumatoid arthritis severity. Ann Rheum Dis. 2010;69(11): 1920-1925.

6. Sandoo A, Veldhuijzen van Zanten JJ, Metsios GS, Carroll D, Kitas GD. Vascular function and morphology in rheumatoid arthritis: a systematic review. Rheumatology (Oxford). 2011;50(11):2125-2139.

7. Mathieu S, Pereira B, Dubost JJ, Lusson JR, Soubrier M. No significant change in arterial stiffness in RA after 6 months and 1 year of rituximab treatment. Rheumatology. 2012;51(6):1107-1111.

8. Arnett FC, Edworthy SM, Bloch DA, McShane DJ, Fries JF, Cooper NS, et al. The American Rheumatism Association 1987 revised criteria for the classification of rheumatoid arthritis. Arthritis Rheum. 1988;31:315-24.

9. Wilkinson IB, Fuchs SA, Jansen IM, Spratt JC, Murray GD, Cockcroft JR Reproducibility of velocity and augmentation index measured by analysis. J Hypertens. 1998;16:2079-2084. 
10. Boutouyrie P, Vermeersch SJ. Reference values for arterial stiffness' collaboration. Determinants of pulse wave velocity in healthy people and in the presence of cardiovascular risk factors: "establishing normal and reference values" European Heart Journal. 2010;31(19):2338-2350.

11. Laurent S, Cockcroft J, van Bortel L, et al. European network for noninvasive investigation of large arteries. Expert consensus document on arterial stiffness: methodological issues and clinical applications. European Heart Journal. 2006;27(21):2588-2605.

12. Dulai R, Perry M, Twycross-Lewis R, Morrissey D, Atzeni F, Greenwald $\mathrm{S}$. The effect of tumor necrosis factor- $\alpha$ antagonists on arterial stiffness in rheumatoid arthritis: a literature review. Semin Arthritis Rheum. 2012;42(1):1-8

13. Kume K, Amano K, Yamada S, Hatta K, Ohta H, Kuwaba N. Tocilizumab monotherapy reduces arterial stiffness as effectively as etanercept or adalimumab monotherapy in rheumatoid arthritis: an open-label randomized controlled trial. J Rheum. 2011;38(10):2169-2171.

14. Protogerou AD, Zampeli E, Fragiadaki K, Stamatelopoulos K, Papamichael C, Sfikakis PP. A pilot study of endothelial dysfunction and aortic stiffness after interleukin-6 receptor inhibition in rheumatoid arthritis. Atherosclerosis. 2011;219(2):734-736.

15. Interleukin-6 Receptor Mendelian Randomisation Analysis (IL6R MR) Consortium, Hingorani AD, Casas JP. The interleukin-6 receptor as a target for prevention of coronary heart disease: a mendelian randomisation analysis. Lancet. 2012;379(9822):1214-1224.

16. Characteristics of tocilizumab. European Medicines Agency; 2009. Available from: http:/www.ema.europa.eu/docs/en_GB/document_ library/EPAR_-_Product_Information/human/000955/WC500054890. pdf. Accessed November 9, 2013.

17. Bannwarth B, Richez C. Clinical safety of tocilizumab in rheumatoid arthritis. Expert Opin Drug Saf. 2011;10(1):123-131.

18. Kawashiri SY, Kawakami A, Yamasaki S, et al. Effects of the antiinterleukin-6 receptor antibody, tocilizumab, on serum lipid levels in patients with rheumatoid arthritis. Rheumatol Int. 2011;31(4):451-456.

19. Hansel B, Bruckert E. [Lipid profile and cardiovascular risk in patients with rheumatoid arthritis: Effect of the disease and of drug therapy]. Ann Endocrinol (Paris). 2010;71(4):257-263. French.

20. Popa C, Netea MG, Radstake T, et al. Influence of anti-tumour necrosis factor therapy on cardiovascular risk factors in patients with active rheumatoid arthritis. Ann Rheum Dis. 2005;64(2):303-305.
21. Dahlqvist SR, Engstrand S, Berglin E, Johnson O. Conversion towards an atherogenic lipid profile in rheumatoid arthritis patients during longterm infliximab therapy. Scand J Rheumatol. 2006;35(2):107-111.

22. Vis M, Nurmohamed MT, Wolbink G, et al. Short term effects of infliximab on the lipid profile in patients with rheumatoid arthritis. J Rheumatol. 2005;32(2):252-255.

23. Allanore Y, Kahan A, Sellam J, Ekindjian OG, Borderie D. Effects of repeated infliximab therapy on serum lipid profile in patients with refractory rheumatoid arthritis. Clin Chim Acta. 2006;365(1-2): 143-148.

24. Kiortsis DN, Mavridis AK, Filippatos TD, Vasakos S, Nikas SN, Drosos AA. Effects of infliximab treatment on lipoprotein profile in patients with rheumatoid arthritis and ankylosing spondylitis. J Rheumatol. 2006;33(5):921-923.

25. Soubrier M, Jouanel P, Mathieu S, et al. Effects of anti-tumor necrosis factor therapy on lipid profile in patients with rheumatoid arthritis. Joint Bone Spine. 2008;75(1):22-24.

26. Payet S, Pereira B, Soubrier M, Mathieu S. The effects of TNF-alpha blocking therapy on lipid levels in rheumatoid arthritis: a meta-analysis. Semin Arthritis Rheum. 2012;41(4):e4-e5.

27. Daïen CI, Duny Y, Barnetche T, Daurès JP, Combe B, Morel J. Effect of TNF inhibitors on lipid profile in rheumatoid arthritis: a systematic review with meta-analysis. Ann Rheum Dis. 2012;71(6):862-868.

28. van Sijl AM, Peters MJ, Knol DL, et al. The effect of TNF-alpha blocking therapy on lipid levels in rheumatoid arthritis: a meta-analysis. Semin Arthritis Rheum. 2011;41(3):393-400.

29. Kerekes G, Soltész P, Dér H, et al. Effects of rituximab treatment on endothelial dysfunction, carotid atherosclerosis, and lipid profile in rheumatoid arthritis. Clin Rheumatol. 2009;28(6):705-710.

30. Schimmel EK, Yazici Y. Increased lipid levels but unchanged atherogenic index in rheumatoid arthritis patients treated with biologic disease modifying antirheumatic drugs: published experience. Clin Exp Rheumatol. 2009;27(3):446-451.

31. Barnabe C, Martin BJ, Ghali WA. Systematic review and meta-analysis: anti-tumor necrosis factor $\alpha$ therapy and cardiovascular events in rheumatoid arthritis. Arthritis Care Res (Hoboken). 2011;63(4): $522-529$.
Biologics: Targets \& Therapy

\section{Publish your work in this journal}

Biologics: Targets \& Therapy is an international, peer-reviewed journal focusing on the patho-physiological rationale for and clinical application of Biologic agents in the management of autoimmune diseases, cancers or other pathologies where a molecular target can be identified. This journal is indexed on PubMed Central, CAS, EMBase, Scopus

\section{Dovepress}

and the Elsevier Bibliographic databases. The manuscript management system is completely online and includes a very quick and fair peerreview system, which is all easy to use. Visit http://www.dovepress com/testimonials.php to read real quotes from published authors. 